\title{
Cutlery matters: heavy cutlery enhances diners' enjoyment of the food served in a realistic dining environment
}

\author{
Charles Michel $^{1{ }^{*+}}$, Carlos Velasco ${ }^{1,2^{* \dagger}}$ and Charles Spence ${ }^{1}$
}

\begin{abstract}
Background: We report a study conducted in a realistic dining environment, in which two groups of diners were served the same three-course meal. The presentation of the starter (centred vs. offset plating), the type of cutlery used for the main course, and the shape and colour of the plate on which that dessert was served were varied.

Results: The results revealed that the weight and type of the cutlery exerted a significant impact on how artistically plated the main course was rated as being, how much the diners liked the food, and how much they would have been willing to pay for it. The change in the shape and colour of the plate also affected the diners' liking for the dessert.

Conclusions: Taken together, these results show that the diners' appreciation of the food is affected by the type of the cutlery used to eat (in this case, knife and fork), in terms of liking, aesthetic value, and willingness to pay for the food, adding to a growing body of gastrophysics research highlighting the importance of food-extrinsic factors in modulating the diner's opinion of the meal that they have been served.
\end{abstract}

Keywords: Food liking, Dining, Perception, Cutlery, Weight, Gastrophysics, Realistic dining

\section{Background}

The recent interest in trying to understand eating experiences through the lens of psychological and sensory research (what sometimes comes under the header 'gastrophysics') is increasingly highlighting the fact that the pleasure and enjoyment of food does not depend solely on the edible elements laid out on the plate. For instance, the latest research has demonstrated how plating, or the art of creating visual compositions with food on a plate, can significantly affect the diner's perception of a dish [1-3]. In other words, while the organoleptic properties of the culinary preparations are fundamental in determining the likely enjoyment of a dish in the mind of the diner, our food experiences are also influenced by visual and structural arrangement of the elements on the plate, among other factors (such as the internal state of the diner, e.g., alliesthesia [4]).

\footnotetext{
* Correspondence: charles.michel@psy.ox.ac.uk; carlosvelasco@protonmail. com

${ }^{\dagger}$ Equal contributors

${ }^{1}$ Crossmodal Research Laboratory, Department of Experimental Psychology, University of Oxford, South Parks Road, Oxford OX1 3UD, UK

Full list of author information is available at the end of the article
}

The utensils that we use to eat with can also affect the perceived taste and flavour of the food [3]. For instance, cutlery made with different materials has been shown to modulate the taste of foods such as yoghurt $[5,6]$ as a result of chemical interactions between the food itself and the material of the cutlery. Furthermore, the colour of the cutlery that we use to eat with has also been shown to alter the perception of certain attributes of taste $[5,7]$. In this case, the underlying causes are still not altogether clear: The perceptual changes elicited by the colour of the cutlery might be attributable to particular taste expectations set by the learned associations that we have all internalized with certain colours [8], or perhaps to a difference in colour contrast between the cutlery and the food, leading to the food having a different visual appearance [9]. Moreover, the haptic ${ }^{1}$ qualities of the eating utensils that we use to bring the food from plate to mouth might also be expected to exert a significant influence on our appraisal of the quality of the food served (see [10,11] for examples of related research assessing the touch and feel of drinking vessels and [12, 13] for reviews on the importance of touch/haptic feedback in the context of gastronomy/beverage perception). 
Of particular interest here, it has been demonstrated that the weight of the eating utensils can influence the perceived value of the food [14], and that the weight of the product/packaging itself (a bottle of wine) [15] seems to implicitly affect our appraisal of the quality and value of the foodstuff, and how much we end up eating/drinking [16].

One of the main objectives of gastronomy is to take care of the diner's wellness [17]. Nowadays, it would seem that anyone wanting to optimize the pleasure of the food that they serve and/or eat would benefit from looking beyond the edible elements that are served on the plate, and think a little more about how it is consumed, and with what utensils and vessels. Indeed, as recently advanced by Kringelbach [18], there is much to be gained by developing a better understanding of how the pleasure of food is generated in our minds.

In the present study, we hypothesized that cutlery of better quality could have an influence on the perceived quality of the food consumed with it. Understanding the factors that determine the influence of the cutlery could be of great interest to designers, chefs, and the general public alike.

We would like to stress two approaches that we see as being especially relevant in the endeavour of enhancing our everyday food experiences: First, we argue that multisensory design for eating experiences could benefit from a more widespread application of the research methods taken from the field of experimental psychology, by testing hypothesis in realistic dining environments, such as the commercial restaurant setting used to collect the data reported in the present study. This approach has, we would argue, already started to show its potential $[2,19-21]$. Second, we report on an experiment in which we not only tested the impact of plating but also assessed the impact of two different types of cutlery, an omnipresent but often overlooked set of eating utensils [3], on the perceived value and enjoyment of the food served.

The data reported here was collected at an experimental lunch served at the Sheraton Grand hotel in Edinburgh (http://www.onesquareedinburgh.co.uk/), on 11 September 2014. The plating of the appetizer differed between two groups of diners (see Fig. 1). The main course was the same for everyone, while the type of cutlery that the diners were given to eat with differed between groups (see Fig. 2). The dessert was the same for all of the participants, with the only change being the shape and colour of the plateware on which it was served.

\section{Results}

A summary of the mean ratings and standard deviations of the liking and artistic ratings is presented in Table 1.

\section{Liking}

Significant main effects of dish type, $F(1.829,217.614)=$ 30.352, $p<0.001, \eta_{\mathrm{p}}^{2}=0.203$ (the Greenhouse-Geisser correction was applied), and group, $F(1,119)=9.359, p=$ $0.003, \eta_{p}^{2}=0.073$, were obtained (see Fig. 3 ). The interaction was not significant $(p=0.066)$. Bonferroni-corrected pairwise comparisons revealed that the diners liked both the main course and the dessert more than the appetizer $(p<0.001$, for both comparisons). Moreover, the participants in group 1 liked their food more than those in group $2(p=0.003)$.

Art

A significant main effect of group, $F(1,119)=7.301, p=$ $0.008, \eta_{\mathrm{p}}^{2}=0.058$, and a significant interaction between dish type and group, $F(1,119)=7.389, p=0.008, \eta_{\mathrm{p}}^{2}=0.058$, were obtained. There was no main effect of dish type ( $p=$ 0.496). Pairwise comparisons revealed that the participants in group 1 considered the dishes to be more artistic than those in group $2(p=0.008)$. As for the interaction term, the participants in group 1 considered their main course to be more artistic than those in group $2(p<0.001)$.

\section{WTP}

A significant main effect of dish type, $F(1,119)=387.036$, $p<0.001, \eta_{\mathrm{p}}^{2}=0.765$, and a significant interaction between dish type and group, $F(1,119)=11.377, p=0.001, \eta_{\mathrm{p}}^{2}=$ 0.087 , were obtained. There was no main effect of group $(p=0.368)$. The diners were willing to pay more for their main course than for their appetizer $(p<0.001)$, as might have been expected. Pairwise comparisons on the interaction term revealed that those diners in group 1 would have been willing to pay significantly more for their main course than those in group $2(p=0.039)$.

\section{Discussion}

Despite the fact that all of the diners in the present study were served exactly the same amount of the same food, there were clear and significant differences in terms of the enjoyment of the food, especially for the main course. The cutlery used to bring the food from plate to mouth, clearly an external factor to the food itself, substantially affected the participants' ratings of the food. In particular, the main course was considered more artistic, was liked more, and the diners would have been willing to pay more for it when eating with the banquet cutlery, as compared to the group given the canteen cutlery. The dessert was liked more when it was served on a square black plate than when served on a round white plate instead ( $M=5.6$ vs. 4.8$)$. However, in this case, no significant changes in terms of the sweetness or flavour intensity were reported. 

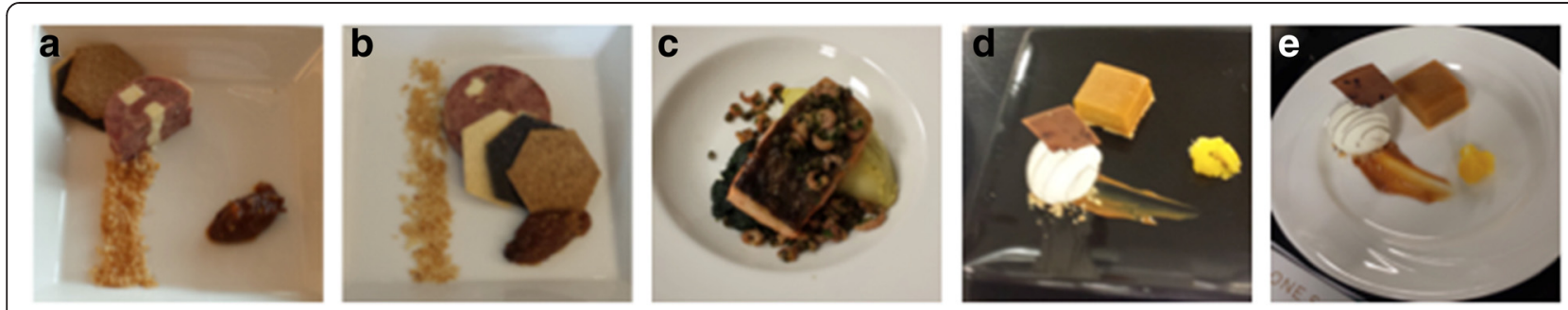

Fig. 1 The three courses served in the present study. The appetizer, a Ploughmans, ham haugh \& Isle of Mull cheddar terrine with apple chutney \& sourdough crisp bread was plated in either an 'offset' (a) or 'centred' manner (b). The main course, a Seared Loch Etive sea trout with mashed potatoes, leaf spinach \& caper, and smoked brown shrimp butter (c), was presented with different cutlery (either lighter, canteen cutlery or heavier, banquet cutlery). The dessert, a Treacle tart with clotted cream ice cream, was either plated on a square black plate (d) or else on a round white plate (e)

\section{Can cutlery enhance the enjoyment of food?}

Analysis of the data from the main course revealed significant differences for all three of the response measures: The food eaten with the aid of the banquet cutlery was liked significantly more $(M=5.7$ vs. 5.1$)$, was rated as significantly more artistic $(M=5.0$ vs. 4.0$)$, and the diners would have been willing to pay significantly more for it $(M=£ 13.9$ vs. $£ 12.0)$. Bearing in mind that the diners in the present study all consumed the same food, these results demonstrate that the multisensory (i.e. the visual and/or haptic) properties of the cutlery can exert a significant effect on our enjoyment of food and on our perception of its value.

As observed in this study, there are several sensory properties of the cutlery that could possibly modulate the enjoyment of food. As mentioned earlier, the material properties of the cutlery (in terms of the metal used) can impact a diner's perception of the intensity of certain basic tastes that are present in a food [5, 6]. However, the metal of the cutlery (stainless steel)

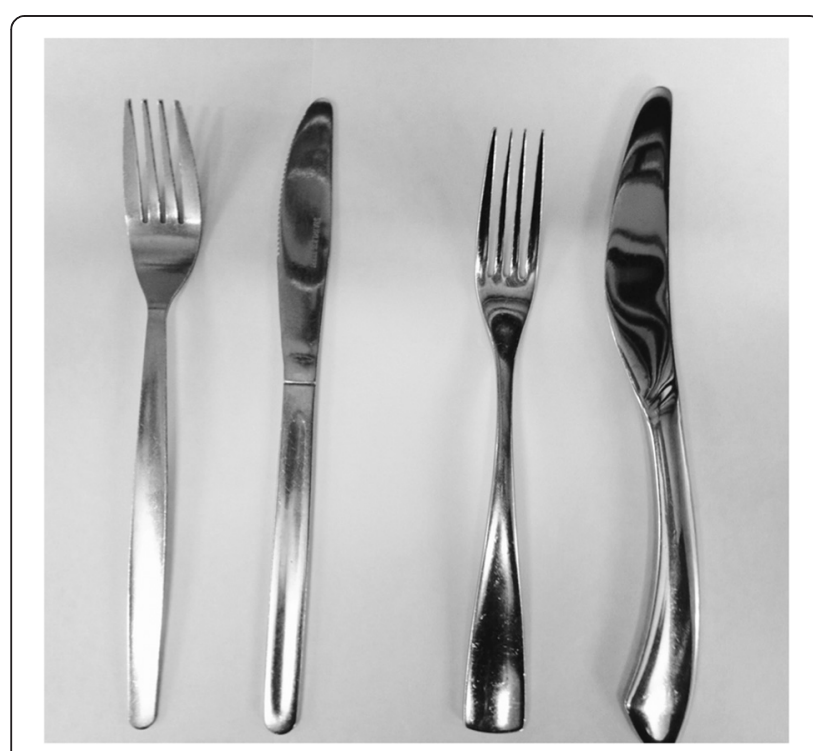

Fig. 2 On the left, the 'canteen' cutlery; on the right, the 'banquet' cutlery was held constant in the present study. Rather, the appearance and feel of the cutlery seems to have been the essential variable that changed/enhanced the diners' perception of the main course. ${ }^{6}$ While it is likely that the pleasantness (or aesthetic properties) of the cutlery can affect what people think about it, recent research ${ }^{7}$ has demonstrated that the weight of the utensil that is used to eat with can affect people's ratings of food $[3,7,14,15]$. These studies, however, were mainly conducted in the laboratory setting, and the effects of weight on perceived food quality has never been measured in a realistic dining setting.

The important differences in the ratings of the food observed by modifying the type of cutlery (differing in look and feel, with a significant difference in weight) suggest that the overall positive (or negative) values attributed to the cutlery implicitly modify the perceived enjoyment of the food. It could be argued that the diners' feelings about the sensory properties of the cutlery were 'transferred' to the food-a phenomenon that often goes by the name of 'sensation transference' [10]. This term has been used to describe the tendency for a given sensory attribute to be rated more positively than would otherwise be the case due to other positive sensory influences, thus transferring sensations from the container to the product. Note that other researchers have used the term 'halo effect' in order to describe a similar phenomenon $[3,22,23]$. Alternatively, the

Table 1 Summary of mean values and standard deviation of the ratings for each group and dish condition

\begin{tabular}{|c|c|c|c|c|c|c|c|}
\hline \multirow[t]{2}{*}{ Group } & \multirow[t]{2}{*}{ Dish } & \multicolumn{2}{|c|}{ Liking } & \multicolumn{2}{|l|}{ Art } & \multicolumn{2}{|l|}{ Price } \\
\hline & & $M$ & SD & $M$ & SD & $M$ & SD \\
\hline \multirow[t]{3}{*}{1} & Appetizer & 4.19 & 1.52 & 4.74 & 1.40 & 4.69 & 2.59 \\
\hline & Main & 5.67 & 1.10 & 4.97 & 1.31 & 13.90 & 5.27 \\
\hline & Dessert & 5.58 & 1.15 & - & - & - & - \\
\hline \multirow[t]{3}{*}{2} & Appetizer & 4.15 & 1.61 & 4.43 & 1.47 & 5.48 & 2.83 \\
\hline & Main & 5.10 & 1.28 & 4.05 & 1.36 & 11.98 & 4.70 \\
\hline & Dessert & 4.78 & 1.54 & - & - & - & - \\
\hline
\end{tabular}



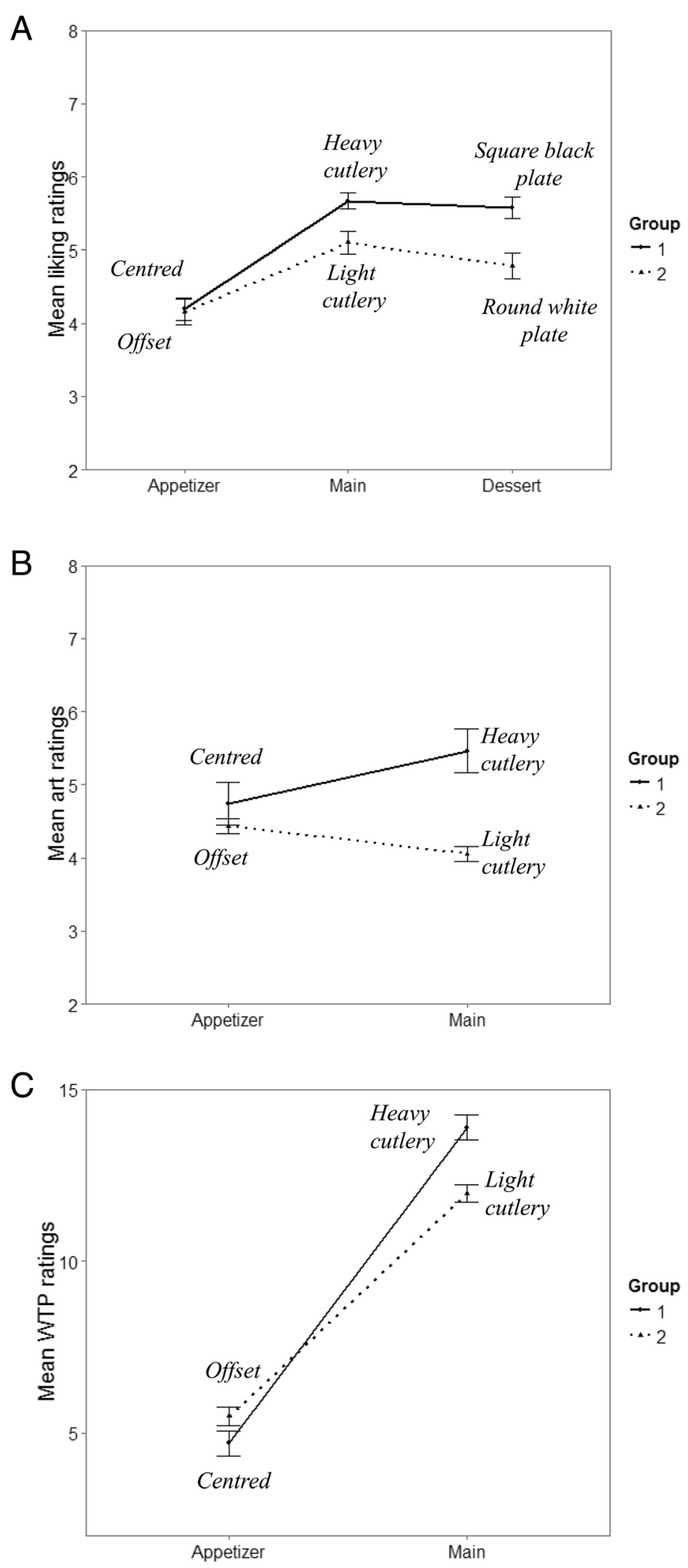

Fig. 3 Summary of main effects of plating for the appetizer (a), cutlery type (heavy vs. light) for the main course (b), and type of plateware for the dessert (c). The error bars correspond to the standard errors of the means 
mechanism driving the effects observed in this study could be attentional in nature. Indeed, it could be hypothesized that the heavier weight of the eating utensils would have captured the attention of the diners more and thus heighten their awareness of the sensory properties of the food [24].

The diners (conference delegates) who came to eat at the dining room/restaurant of Edinburgh's Sheraton Grand Hotel in the present study will likely have associated the venue with a high-end dining experience. It is therefore possible that those diners who were given the cheaper (lighter) cutlery to eat their main course with might implicitly have registered a mismatch between the cutlery and the environment in which that cutlery was being used [25].

While it now seems plausible that the weight and perceived value of the cutlery affect the enjoyment of the food, with perceived quality being transferred from the cutlery to the food in an implicit manner, further research is undoubtedly still needed in order to clarify which of the cutlery's sensory properties affects the enjoyment of the food and, in particular, how weight, tactile, and visual aesthetics interact, and by which perceptual mechanisms.

\section{Is it the plate or its colour?}

The difference in the liking of the dessert is consistent with previous studies showing that plateware affects people's ratings of food [26-28]. At least part of the influence of the colour of the plate might be interpreted in terms of the colour contrast between the food and the plate against which that food is seen $[3,9]$. However, given that both the colour and shape of the plate were varied between groups [28], we cannot unravel the effects of the attributes (or an interaction between them) that may have caused the higher preference for the dessert served on the square black plate. Interestingly, informal reports suggested that a number of diners found the dessert served in this study to have been a little too sweet. So while a number of studies now concur in demonstrating that the colour and/or, on occasion, the shape of the plate can affect people's ratings of the taste and quality of the food [26-28], the direction of that change, and whether or not it is liked more, will likely depend on the underlying response of the diners to the food substrate itself. So, for instance, a dessert that is already 'too sweet' may be preferred when served from a black plate, whereas a dessert that may be judged as not quite sweet enough may be preferred from a white plate instead.

\section{Limitations}

While the present study provides evidence for the idea that the different elements that accompany the experience of eating influence the experience of the food, a few limitations should be mentioned. For example, the participants were not given a definition of what 'artistic' meant, and so some variability between participants in terms of their response to this item may be expected. Furthermore, the participants could decide where they wanted to sit, which may potentially have biased the results in that they may have grouped themselves as a function of common characteristics. Each table seated several participants, which could have led to a group effect in case comments about the cutlery were exchanged; this is the reason why, in sensory tests, care is taken so that each participant evaluates the stimuli alone.

Here, we would argue that naturalistic studies may require some trade-offs, given that laboratory studies have long been criticized for their lack of ecological validity. Measuring effects in realistic environments can be of interest despite the difficulty of gaining completely quantitative data, and we believe that the science of flavour and of dining could benefit from an integration of naturalistic with laboratory studies.

Further research could also assess the impact of the weight of the cutlery on perceived satiety, food intake, and consumption behaviour, which might be the fact why participants eating with the heavier/banquet cutlery responded more favourably to the questions regarding the food.

\section{Conclusions}

The results presented here reveal a simple but essential fact: The diners' appreciation of the food is affected by the type of the cutlery used to eat (in this case, knife and fork were changed between experimental groups), in terms of liking, aesthetic value, and WTP for the food. In other words, a very common set of utensils, present on tables around the world, can potentially make the food 'taste' better (or worse). These results also bring further evidence to the notion that the shape and colour of the plate on which the food is served can affect how much diners enjoy food.

The methodological approach outlined here illustrates the potential of large-scale dining events to evaluate the responses of diners to a variety of cues of the eating experience. Results from studies such as the one reported here provide evidence to support the claim that, in the endeavor of creating a pleasurable meal, there is more to deliciousness than just the food on the plate. Indeed, cues as seemingly extraneous to the food experience as the tool that is used to bring the food from plate to mouth can enhance the perceived value and enjoyment of food. While we agree with the fact that the tangible aspects of deliciousness reside in the molecular and physical properties of foodstuffs, the scientific literature 
now shows how multisensory design really can affect flavour perception and our enjoyment of food and drink. It would now seem evident that the everything else - the " service' - truly matters (see [3] for a thorough review of the literature pointing in this direction). We think that evidence such as the findings reported in this article bring additional insights into how to make food more enjoyable in the restaurant scene, and in everyday life.

\section{Methods}

\section{Participants}

The participants consisted of the delegates attending an international conference $(N=134,87$ males, 31 females, with 16 failing to specify). The mean age $(M=49.1$ years, $\mathrm{SD}=11.76$, from $20-76$ years) was calculated on the basis of the 124 responses where age information was provided. The data from 13 of the participants was excluded from the analysis due to their failure to complete the score sheet, leaving a total of 121 participants $(M=49$ years, $\mathrm{SD}=11.84$, from $20-76$ years, calculated from 113 participants who provided the relevant information) including 82 males, 29 females, and 10 who failed to specify.

\section{Apparatus and materials}

The impact of three different manipulations was measured. (1) The starter consisted of a Ploughmans, ham haugh $\mathcal{E}$ Isle of Mull cheddar terrine with apple chutney $\mathcal{E}$ sourdough crisp bread. For group $1(N=62)$, the starter was placed in the centre of the plate, while group $2(N=59)$ had it served offset slightly to one side of the plate (the food items were presented off the central vertical axis of the plate, see Fig. 1). This manipulation was inspired by the findings by Michel et al. [19], where the same food was preferred when placed in the centre of the plate, as opposed to off to one side. (2) The main course consisted of Seared Loch Etive sea trout with mashed potatoes, leaf spinach $\mathcal{E}$ caper, and smoked brown shrimp butter. Group 1 used the higher-quality cutlery normally used for banquets ${ }^{2}$ (to which we will now refer as banquet cutlery) while group 2 used a more conventional, lower-quality cutlery, normally used in the hotel's staff canteen ${ }^{3}$ (from now on referred to as canteen cutlery). The design of the two types of cutlery can be seen in Fig. 2. The banquet fork weighed $84 \mathrm{~g}$, while the canteen fork weighed in at $26 \mathrm{~g}$. The banquet knife weighed $132 \mathrm{~g}$, and the canteen knife, $38 \mathrm{~g}$. (3) The dessert consisted of Treacle tart with clotted cream ice cream: Group 1 had their dessert served on a square black plate, while group 2 had the same dessert on a round white plate instead (see Fig. 1).

\section{Procedure}

The dining room was divided into two groups of tables, with places set with a pink score sheet at half of the tables and green score sheets at the remainder. Upon entering the dining room, the guests were allowed to sit wherever they wanted. The guests were given the same cutlery with which to eat their appetizer and dessert, while for the main course, the waiters were instructed to place the canteen (light) cutlery for the tables with pink score sheets, while the guests sitting at the other tables (with green score sheets) were given the banquet (heavy) cutlery instead. Both groups were served exactly the same food, but plated in different manners for the appetizer and dessert. The participants were not aware of the particular experimental manipulations between groups, given the disposition of the tables. This study was approved by Oxford University's Medical Sciences Inter-Divisional Research Ethics Committee (MS-IDREC-C1-2015-058). The data collection was conducted in accordance with the Declaration of Helsinki, and informed consent was obtained from all of the participants/diners.

One of the authors (CS) introduced the diners to the event and informed them that they would be taking part in a series of experiments regarding food and that they would be asked to answer a questionnaire after each course. The diners were informed that they did not have to complete the forms should they not want to. Given the nature of the study and the occasion on which it was held, the decision was made to keep the questionnaire as brief and simple as possible (no demographic data concerning the participants was collected). The questionnaires were presented on A4 sheets of paper. For the appetizer and main course, the questions aimed to measure the diners' liking for the presentation, how artistically ('art') the food elements seemed to be arranged on the plate, and how much they would have been willing to pay (WTP) for each of the dishes. ${ }^{4}$ For the dessert, the questions ${ }^{5}$ assessed the delegates' liking, and the sweetness and flavour intensity, of the food. The liking (How much do you like this dish?) and the art (How artistic would you say the plating is?) variables were assessed by means of 7-point Likert scales anchored with 'not at all' (1) and 'very much' (7).

\section{Analysis}

The liking ratings were analyzed by means of a mixed design analysis of variance (ANOVA) with dish type (appetizer, main course, dessert) as the within-participant factor and group (1 vs. 2) as a between-participants factor. The art and WTP ratings were analyzed by means of a mixed design ANOVA with dish type (appetizer and main course) as the within-participants factors, and group (1 vs. 2 ) as the between-participants factor (see Fig. 3 for a summary of the results). Note that the sweetness $(M=5.43$, $\mathrm{SD}=1.09$ for group 1 and $M=5.42, \mathrm{SD}=1.30$ for group 2 ) and intensity $(M=5.36, \mathrm{SD}=1.11$ for group 1 and $M=$ $5.08, \mathrm{SD}=1.38$ for group 2) ratings of the dessert were 
analyzed with two independent-samples $t$ tests. However, no significant differences were observed for these ratings.

\section{Endnotes}

${ }^{1}$ By haptic, we refer to the tactile and proprioceptive properties of the eating utensils that include, but are not limited to, texture, shape, weight, and density.

${ }^{2}$ 'Reflections' range, made by Wedgwood.

${ }^{3}$ New Era' range made by Signature steel exclusively for Lockhart's, one of the Sheraton grand Hotel \& Spa suppliers, in Edinburgh.

${ }^{4}$ Note that the diners were invited by the conference organization; hence, they did not actually have to pay for the food.

${ }^{5}$ For the dessert, the questions were formulated as follows: "How much do you like this dessert?", "How sweet does it taste?", and "How intense is the flavour?"

${ }^{6}$ There is clearly a field for innovative design opening up here, with a growing number of chefs becoming increasingly interested in collaborating with designers. In some cases, the boundary between the plateware and the cutlery is starting to blur [29]. Note also that designers are increasingly starting to explore the multisensory properties of the cutlery.

${ }^{7}$ It is, however, important to note that the strength of the within-participants experimental designs utilized in these previous studies was offset by the possibility of having participants rate the same food with spoons of different weights. Thus, the explicit manipulation of weight may have drawn the participants' attention to subtle (or not so subtle) differences in weight in a manner that may not have been so apparent in an everyday dining situation, where we normally eat a dish using only one set of cutlery.

\section{Abbreviation}

WTP: willingness to pay.

\section{Competing interests}

The authors declare that they have no competing interests.

\section{Authors' contributions}

CS designed the experiment and collected the data. CV and CM performed the statistical analyses. All contributed to the writing of the paper. All of the authors read and approved the final version of the manuscript.

\section{Acknowledgements \\ Special thanks to the International Egg Commission 2014 Global Leadership Conference and the Sheraton Grand Hotel, Edinburgh, for allowing us to conduct this experiment. CS would like to thank the Arts and Humanities Research Council (AHRC) for funding the Rethinking the Senses grant ( $\mathrm{AH}$ ) L007053/1).}

\section{Author details}

${ }^{1}$ Crossmodal Research Laboratory, Department of Experimental Psychology, University of Oxford, South Parks Road, Oxford OX1 3UD, UK. ${ }^{2}$ Imagineering Institute, IDM Lab Sdn. Bhd, Anchor 5, Mall of Medini, No. 4, Lebuh Medini Utara, Medini, Iskandar, Nusajaya 79250Johor, Malaysia.
Received: 9 April 2015 Accepted: 2 July 2015

Published online: 23 July 2015

\section{References}

1. Michel C, Velasco C, Gatti E, Spence C. A taste of Kandinsky: assessing the influence of the artistic visual presentation of food on the dining experience. Flavour. 2014;3:11.

2. Zellner DA, Loss CR, Zearfoss J, Remolina S. It tastes as good as it looks! The effect of food presentation on liking for the flavor of food. Appetite. 2014;77C:31-5.

3. Spence C, Piqueras-Fiszman B. The perfect meal: the multisensory science of food and dining. Oxford, UK: Wiley-Blackwell; 2014.

4. Jiang $T$, Soussignan R, Rigaud D, Martin S, Royet JP, Brondel L, et al. Alliesthesia to food cues: heterogeneity across stimuli and sensory modalities. Physiol Behav. 2008;95:464-70.

5. Piqueras-Fiszman B, Laughlin Z, Miodownik M, Spence C. Tasting spoons: assessing how the material of a spoon affects the taste of the food. Food Qual Prefer. 2012;24:24-9.

6. Laughlin Z, Conreen M, Witchel HJ, Miodownik M. The use of standard electrode potentials to predict the taste of solid metals. Food Qual Prefer. 2011;22:628-37.

7. Harrar V, Spence $C$. The taste of cutlery: how the taste of food is affected by the weight, size, shape, and colour of the cutlery used to eat it. Flavour. 2013;2:13.

8. Spence C, Wan X, Woods A, Velasco C, Deng J, Youssef J, et al. On tasty colours and colourful tastes? Assessing, explaining, and utilizing crossmodal correspondences between colours and basic tastes. Flavour. 2015:4:23.

9. Lyman B. A psychology of food, more than a matter of taste. New York, NY: Van Nostrand Reinhold; 1989.

10. Krishna A, Morrin M. Does touch affect taste? The perceptual transfer of product container haptic cues. J Consum Res. 2008;34:807-18.

11. Schifferstein HNJ. The drinking experience: cup or content? Food Qual Prefer. 2009;20:268-76

12. Spence $C$, Hobkinson C, Gallace A, Piqueras-Fiszman B. A touch of gastronomy. Flavour. 2013;2:14.

13. Spence C, Wan I. Beverage perception and consumption: the influence of the container on the perception of the contents. Food Qual Prefer. 2015;39:131-40

14. Piqueras-Fiszman B, Harrar V, Roura E, Spence C. Does the weight of the dish influence our perception of food? Food Qual Prefer. 2011;22:753-6.

15. Piqueras-Fiszman B, Spence C. The weight of the bottle as a possible extrinsic cue with which to estimate the price (and quality) of the wine? Observed correlations. Food Qual Prefer. 2012;25:41-5.

16. Piqueras-Fiszman B, Spence $C$. The weight of the container influences expected satiety, perceived density, and subsequent expected fullness. Appetite. 2012;58:559-62.

17. Brillat-Savarin JA: Physiologie du goût [The philosopher in the kitchen/The physiology of taste]; 1835. Translated by A. Lalauze: A handbook of gastronomy. London: Nimmo \& Bain; 1884

18. Kringelbach ML. The pleasure of food: underlying brain mechanisms of eating and other pleasures. Flavour. 2015;4:20.

19. Michel C, Velasco C, Fraemohs P, Spence C. Studying the impact of plating on ratings of the food served in a naturalistic dining context. Appetite. 2015;90:45-50

20. Spence C, Velasco C, Knoeferle K. A large sample study on the influence of the multisensory environment on the wine drinking experience. Flavour. 2014;3:8.

21. Velasco C, Jones R, King S, Spence C. Assessing the influence of the multisensory environment on the whisky drinking experience. Flavour. 2013;2:23.

22. Cheskin L. How to predict what people will buy. New York, NY: Liveright; 1957.

23. Lawless HT, Heymann H. Sensory evaluation of food: principles and practices. New York, NY: Chapman \& Hall; 1997.

24. Woods AT, Poliakoff E, Lloyd DM, Kuenzel J, Hodson R, Gonda H, et al. Effect of background noise on food perception. Food Qual Prefer. 2011;22:42-7.

25. García-Segovia P, Harrington RJ, Seo HS. Influence of table setting and eating location on food acceptance and intake. Food Qual Prefer. 2015;39:1-7.

26. Piqueras-Fiszman B, Alcaide J, Roura E, Spence C. Is it the plate or is it the food? Assessing the influence of the color (black or white) and shape of the plate on the perception of the food placed on it. Food Qual Prefer. 2012;24:205-8 
27. Piqueras-Fiszman B, Giboreau A, Spence C. Assessing the influence of the colour/finish of the plate on the perception of the food in a test in a restaurant setting. Flavour. 2013;2:24.

28. Stewart PC, Goss E. Plate shape and colour interact to influence taste and quality judgments. Flavour. 2013;2:27.

29. Deroy O, Michel C, Piqueras-Fiszman B, Spence C. The plating manifesto (I): from decoration to creation. Flavour. 2014;3:6.

Submit your next manuscript to BioMed Central and take full advantage of:

- Convenient online submission

- Thorough peer review

- No space constraints or color figure charges

- Immediate publication on acceptance

- Inclusion in PubMed, CAS, Scopus and Google Scholar

- Research which is freely available for redistribution 